intensity measured by flow cytometry of the infected macrophages was 2-fold higher after $24 \mathrm{~h}$ of macrophage infection with strain RB51pNSGroE/GFP relative to those infected with strain RB51pBBGroE/GFP (data not shown).

In order to study the expression of Escherichia coli $\beta$-galactosidase in $B$. abortus strain RB51, a 2.9-kb insert containing the $l a c Z$ gene was excised from $\mathrm{pRSETB} / \beta$-gal (Invitrogen) and cloned into pNSGroE and pBBGroE, The expression of $\beta$-galactosidase and enzyme activity, as calculated in modified Miller units, was compared between strain RB51pNSGroE/LacZ and RB51pBBGroE/LacZ. Without any heat-shock stimulus, the enzyme activity in strain RB51pNSGroE/LacZ was approximately twice compared to that expressed by strain RB51pBBGroE/ LacZ. The $\beta$-galactosidase activity in both strains increased by $25 \%$ after heat-shock treatment for $20 \mathrm{~min}$, reflecting a characteristic feature of the groE promoter.

Previous studies have shown that pBBR1MCS replicates and is stably maintained in all Brucella spp. (6). Therefore, the pNSGroE expression vector should also be useful in all $\mathrm{Bru}$ cella spp. So far, we have expressed GFP and red fluorescence protein (RFP) successfully in B. abortus strain 2308 and Ochrobactrum anthropi strain 49237 (Figure 2C).

These data suggest that heterologous genes cloned in pNSGroE plasmid are expressed at higher levels than the same genes cloned in pBBGroE, even though in both these plasmids, expression of the cloned genes was driven by the same Brucella groE promoter. The difference may be attributable to the increased copy number due to decreased size of the pNSGroE plasmid.

\section{ACKNOWLEDGMENTS}

Appreciation is expressed to Dr. John McDowell (Virginia Tech) for his suggestions. We would like to thank Mrs. Kay Carlson, Dr. Abey Bandara, and Ms. Sheela Ramamoorthy of the Center for Molecular Medicine and Infectious Disease (CMMID) at Virginia Tech for their advice and support.

\section{COMPETING INTERESTS STATEMENT}

The authors declare no conflicts of interest.

\section{REFERENCES}

1.Kovach, M.E., R.W. Phillips, P.H. Elzer, R.M. Roop II, and K.M. Peterson. 1994. pBBR1MCS: a broad-host-range cloning vector. BioTechniques 16:800-802.

2.Vemulapalli, R., Y. He, S.M. Boyle, N. Sriranganathan, and G.G. Schurig. 2000. Brucella abortus strain RB51 as a vector for heterologous protein expression and induction of specific Th1 type immune responses. Infect. Immun. 68:3290-3296.

3.Antoine, R. and C. Locht. 1992. Isolation and molecular characterization of a novel broad-host-range plasmid from Bordetella bronchiseptica with sequence similarities to plasmids from Gram-positive organisms. Mol. Microbiol. 6:1785-1799.

4.McQuiston, J.R., G.G. Schurig, N. Sriranganathan, and S.M. Boyle. 1995. Transformation of Brucella species with suicide and broad host-range plasmids. Methods Mol. Biol. 47:143-148.
5.Fernandez-Prada, C.M., E.B. Zelazowska, M. Nikolich, T.L. Hadfield, R.M. Roop II, G.L. Robertson, and D.L. Hoover. 2003. Interactions between Brucella melitensis and human phagocytes: bacterial surface O-polysaccharide inhibits phagocytosis, bacterial killing, and subsequent host cell apoptosis Infect. Immun. 71:2110-2119.

6.Elzer, P.H., M.E. Kovach, R.W. Phillips, G.T. Robertson, K.M. Peterson, and R.M. Roop II. 1995. In vivo and in vitro stability of the broad-host-range cloning vector pBBR1MCS in six Brucella species. Plasmid 33:51-57

Received 28 April 2004; accepted 8 July 2004.

Address correspondence to Nammalwar Sriranganathan, Department of Biomedical Sciences and Pathobiology, Center of Molecular Medicine and Infectious Diseases, Virginia-Maryland Regional College of Veterinary Medicine, Virginia Polytechnic and State University, Blacksburg, VA 240610342,USA.e-mail: nathans@vt.edu

\title{
Method based on electrophoresis and gel extraction for obtaining genomic DNA-free cDNA without DNase treatment
}

\author{
Laura Jaakola, Anna Maria Pirttilä, Jaana Vuosku, and Anja Hohtola \\ University of Oulu, Oulu, Finland
}

BioTechniques 37:744-748 (November 2004)

For studying differential gene expression by reverse-transcriptase PCR (RT-PCR) applications, eliminating genomic DNA contamination from the cDNA is essential prior to amplification of the specific gene sequence. Residual genomic DNA can disturb the amplification of the target gene from cDNA and lead to false-positive results. DNase I treatment is generally used to remove genomic DNA from RNA samples. However, RNA can degrade totally or partially during the DNase treatment. It has also been shown that some contamination of genomic DNA can remain after the DNase treatment, even after an overnight incubation (1). Certain tissue types can be a problem because some contain elevated levels of RNases $(2,3)$ or a limited amount of RNA (4). Fruit tissues are regarded as particularly problematic because of high amounts of secondary metabolites, polysaccharides, and elevated levels of RNases (5). In our experiments with RNA from different plant tissues, especially bilberry (Vaccinium myrtillus) fruit and leaf, we found that RNA degraded during the DNase treatment. We also noticed that despite the DNase treatment, some 
genomic DNA was always left in the samples when RT-PCR gene expression analysis was performed on Scots pine (Pinus sylvestris) needles. To overcome these problems, we developed a method based on electrophoresis and gel-extraction filter tubes.

Bilberry fruits and leaves and Scots pine needles growing in a forest in Oulu, Finland, were snap frozen in liquid nitrogen and stored at $-80^{\circ} \mathrm{C}$ until use. Total RNA was isolated from the samples with the method described for pine trees (6) that had been modified by Jaakola et al. (7). The quality of the isolated RNA was verified on a $1 \%(\mathrm{w} / \mathrm{v})$ ethidium bromide-stained agarose gel and from the absorbance measurements at wavelengths 230,260 , and $280 \mathrm{~nm}$.

From each sample, $5 \mu \mathrm{g}$ were taken for DNase treatment with TURBOTM DNase (Ambion, Austin, TX, USA), according to the manufacturer's instructions (1 U/1 $\mu \mathrm{g}$ DNA) using SUPERase-In ${ }^{\mathrm{TM}}$ RNase inhibitor (Ambion) in a reaction volume of $50 \mu \mathrm{L}$ at $37^{\circ} \mathrm{C}$ for $30 \mathrm{~min}$. Figure $1 \mathrm{~A}$ shows the isolated RNA before and after the DNase treatment. As seen in the figure, RNA from bilberry fruits (lane 6) is totally degraded, and RNA from leaf sample (lane 5) is mostly degraded after the DNase treatment. The RNA from pine needles is still intact, but the amount has been reduced to $1 / 5$ of the original.

In addition, $5 \mu \mathrm{g}$ of each sample of non-DNase-treated RNA were reverse transcribed using Moloney murine leukemia virus (M-MLV) reverse transcriptase (Invitrogen, Carlsbad, CA, USA) with anchored oligo(dT) primers using standard methods in a reaction volume of $20 \mu \mathrm{L}$. The samples were separated for $15 \mathrm{~min}$ at 40 volts (V) on a $1 \%$ ethidium bromide-stained agarose gel prepared in Tris-acetateEDTA (TAE) buffer. The cDNA fragments were trimmed out of the gel according to the size information $(<10$ $\mathrm{kb}$ ), leaving the genomic DNA on the gel (Figure 1B). The fragments were extracted from agarose gel slices with the Montage ${ }^{\circledR}$ DNA Gel Extraction Kit (Millipore, Bedford, MA, USA), which is designed to extract DNA fragments that are 100 to $10,000 \mathrm{bp}$ in size in one 10 -min centrifugation at $5000 \times g$. After the centrifugation, the solution containing the cDNA was precipitated by adding two volumes of ice-cold absolute ethanol, incubating at $-70^{\circ} \mathrm{C}$ for $30 \mathrm{~min}$, and centrifuging at $18,000 \times$ $g$ for $15 \mathrm{~min}$ at $4^{\circ} \mathrm{C}$. The pellet was suspended in $10 \mu \mathrm{L}$ sterilized water.

For verifying the purity of the cDNA from genomic DNA, PCR was performed using the gel-purified cDNA or genomic DNA as template. For the latter, DNA was isolated from pine needles and bilberry leaves with the method described by Pirttilä et al. (8). DyNAzyme $^{\mathrm{TM}}$ DNA polymerase (Finnzymes, Espoo, Finland) was used for the PCR amplification in a final volume of $25 \mu \mathrm{L}$. Conditions for PCR for pine and bilberry cDNA and DNA were 30 cycles of $94^{\circ} \mathrm{C}$ for $60 \mathrm{~s}, 54^{\circ}-63^{\circ} \mathrm{C}$ for $2 \mathrm{~min}$, and $72^{\circ} \mathrm{C}$ for 2 min. Table 1 presents the annealing temperature for each primer. The PCR products were separated on a $1 \%(\mathrm{w} / \mathrm{v})$ agarose gel stained with ethidium bromide. Precise sizes for expected amplification products are given in Table 1; in all cases, the primer pairs encompass a region containing at least one intron, thus allowing cDNA and genomic DNA amplification products to be distinguished. As a first analysis, primer pairs against glyceraldehyde3-phosphate dehydrogenase $(G A P D)$ were used to amplify products from pine and bilberry cDNA and DNA samples (Figure 1C). No bands indicative of genomic DNA contamination were seen in the gel-purified cDNA samples. To confirm the importance of the purification step, additional primer pairs against actin $(A C T)$, chalcone synthase $(\mathrm{CHS})$, and pinosylvin synthase $(B B S)$ were used for amplifying fragments from pine cDNA samples with and without gel separation and from the genomic DNA as a control (Figure 1D). In samples without gel separation, using CHS and BBS primers, the amplification occurred primarily from genomic DNA instead of cDNA. With ACT primers, both cDNA and genomic DNA were equally amplified from the untreated samples (Figure 1D). These results clearly show how

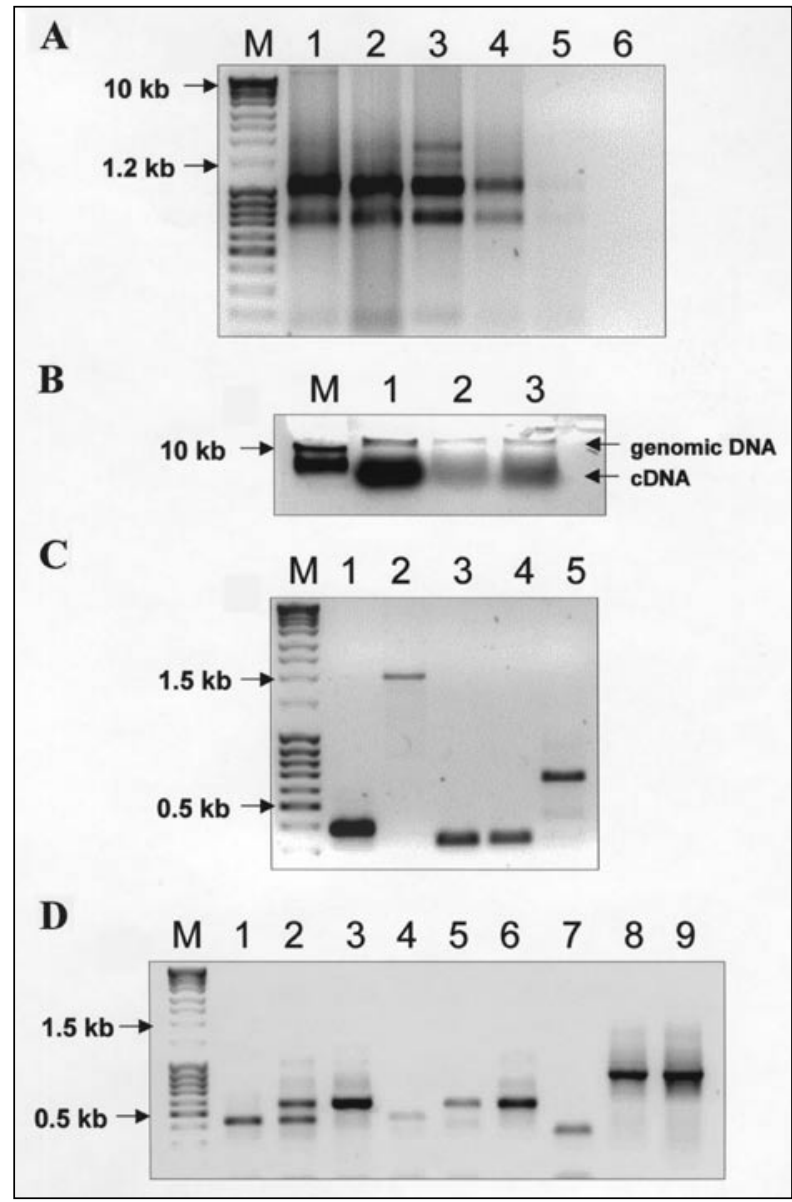

Figure 1. Preparation of genomic DNA-free cDNA. (A) Separation of isolated total RNA $(0.5 \mu \mathrm{g})$ by electrophoresis before (lanes 1-3) and after (lanes 4-6) DNase treatment. Lanes 1 and 4: pine needle RNA; lanes 2 and 5: bilberry leaf RNA; lanes 3 and 6: bilberry fruit RNA. (B) Separation of cDNA from genomic DNA prior to centrifugation at $5000 \times g$ with gel-extraction tubes. Lane 1: pine needle cDNA; lane 2: bilberry leaf cDNA; lane 3: bilberry fruit cDNA. (C) Amplification using glyceraldehyde-3-phosphate dehydrogenase $(G A P D)$ /pine primers of (lane 1) pine cDNA and (lane 2) pine genomic DNA; amplification using GAPD/bilberry primers of (lane 3) bilberry leaf cDNA, (lane 4) bilberry fruit cDNA, and (lane 5) bilberry genomic DNA. (D) Lanes 1, 4, and 7: gel-separated pine cDNA; lanes 2, 5, and 8: pine cDNA without separation; lanes 3, 6, and 9: pine genomic DNA. Lanes 1-3: PCR with actin $(A C T)$ primers; lanes 4-6: PCR with chalcone synthase $(C H S)$ primers; lanes 7-9: PCR with pinosylvin synthase (BBS) primers. In all cases, lane $\mathrm{M}$ corresponds to GeneRuler ${ }^{\mathrm{TM}}$ DNA Ladder Mix (Fermentas, Vilnius, Lithuania). 
Table 1. Sequences of the Primers and Information of the Reaction Conditions and Amplification Products

\begin{tabular}{|c|c|c|c|c|c|c|}
\hline \multirow[b]{2}{*}{ Gene } & \multirow[b]{2}{*}{$\begin{array}{c}\text { GenBank }^{\circledR} \\
\text { No. }\end{array}$} & \multirow[b]{2}{*}{ Primer } & \multirow[b]{2}{*}{ Primer Sequence } & \multirow[b]{2}{*}{$\begin{array}{c}\mathrm{T}_{\mathrm{a}} \\
\left({ }^{\circ} \mathbf{C}\right)\end{array}$} & \multicolumn{2}{|c|}{$\begin{array}{l}\text { PCR Fragment } \\
\text { (bp) }\end{array}$} \\
\hline & & & & & cDNA & gDNA \\
\hline \multirow[t]{2}{*}{ GAPD/pine } & L07501 & GAPDf & 5'-GTCAACGTCAAAGACTCGAA-3' & 54 & 358 & 1500 \\
\hline & & GAPDr & 5'-GTCTTCTGAGTTGCTGTGAT-3' & 54 & & \\
\hline \multirow[t]{2}{*}{$A C T$} & M36171 & ACTf & 5'-GCTTGCTTATGTAGCCCTTGA-3' & 58 & 436 & 570 \\
\hline & & $\mathrm{ACTr}$ & 5'-GGTCTTGGCAATCCACATCT-3' & 58 & & \\
\hline \multirow[t]{2}{*}{$\mathrm{CHS}$} & $\mathrm{X} 60754$ & CHSf & 5'-AACAGCGAGCATATGACAGA-3' & 58 & 442 & 551 \\
\hline & & $\mathrm{CHSr}$ & 5'-TCACTGCAAACAACCAGAAC-3' & 58 & & \\
\hline$B B S$ & $X 60753$ & BBSf & 5'-GAAGGTTTCAGGAAGTTGCAGA-3' & 58 & 360 & 929 \\
\hline
\end{tabular}

the presence of genomic DNA disturbs the amplification of a target gene from cDNA. In quantitative RT-PCR, the results would thus be greatly distorted.

The elimination of genomic DNA from RNA or cDNA is required to study gene expression with RT-PCR or microarrays. A common strategy for removing genomic DNA is DNase treatment; however, typical problems include the degradation of the RNA and the presence of residual contaminating genomic DNA. Our results show that the method described here is suitable for obtaining intact and functional cDNA that is free of genomic DNA. We have found this method useful with all RNA samples, but especially with samples that degrade easily during the DNase treatment step. The method is efficient because no timeconsuming extraction steps with hazardous chemicals are needed. Flohr et al. (9) reported the possibility of performing the DNase treatment on cDNA instead of RNA, which is also an alternative for the RNA samples that degrade easily during the DNase treatment. However, because of the extraction steps, some loss of the sample always occurs during the DNase treatment. Although some reduction in sample amount is also encountered during the gel-extraction step, we have found this method more reliable because residual genomic DNA was frequently detected when DNase treatment was used.

\section{ACKNOWLEDGMENTS}

This work was supported by Academy of Finland, SUNARE project (Sustainable Use of Natural Resources) grant no. 52741, and by the Emil Aaltonen Foundation.

\section{COMPETING INTERESTS STATEMENT}

The authors declare no competing interests.

\section{REFERENCES}

1.Ivarsson, K., and B. Weijdegard. 1998. Evaluation of the effects of DNase treatment on signal specifity in RT-PCR and in situ RTPCR. BioTechniques 25:630-638.

2.Groppe, J.C. and D.E. Morse. 1993. Isolation of full-length RNA templates for reverse transcription from tissues rich in RNase and proteoglycans. Anal. Biochem. 210:337-343.

3.Pillon, D. and G. Bruneau. 2003. Resistant ribonuclease activity in preparations of total RNA extracted from artiodactylbrain with GITC. BioTechniques 34:920-924.

4.Miller, C.L. and R.H. Yolken. 2003. Methods to optimize the generation of cDNA from postmortem human brain tissue. Brain Res. Prot. 10:156-167.

5.Rodrigues-Pousada, R., M. Van Montagu, and D. Van der Straeten. 1990. A protocol for preparation of total RNA from fruit. Technique 2:292-294.

6. Chang, S., J. Puryear, and J. Cairney. 1993. A simple and efficient method for isolating
RNA from pine trees. Plant Mol. Biol. Reptr. 11:113-116.

7.Jaakola, L., A.M. Pirttilä, M. Halonen, and A. Hohtola. 2001. Isolation of high quality RNA from the bilberry (Vaccinium myrtillus L.) fruit. Mol. Biotechnol. 19:201-203.

8.Pirttilä, A.M., T. Kämäräinen, M. Hirsikorpi, L. Jaakola, and A. Hohtola. 2001. A DNA isolation method for medicinal and aromatic plants. Plant Mol. Biol. Reptr. 19:273a-f.

9.Flohr, A.M., T. Hackenbeck, C. Schlueter, P. Rogalla, and J. Bullerdiek. 2003. Dnase I treatment of cDNA first strands prevents RTPCR amplification of contaminating DNA sequences. BioTechniques 35:920-926.

Received 29 April 2004; accepted 13 July 2004.

Address correspondence to Laura Jaakola, Department of Biology/Botany, University of Oulu, P.O. Box 3000, FIN-90014 Oulu, Finland.e-mail: Laura.Jaakola@oulu.fi 